\title{
What's expected of us
}

\author{
It's a tough choice...
}

\section{Ted Chiang}

This is a warning. Please read carefully.

By now you've probably seen a Predictor; millions of them have been sold by the time you're reading this. For those who haven't seen one, it's a small device, like a remote for opening your car door. Its only features are a button and a big green LED. The light flashes if you press the button. Specifically, the light flashes one second before you press the button.

Most people say that when they first try it, it feels like they're playing a strange game, one where the goal is to press the button after seeing the flash, and it's easy to play. But when you try to break the rules, you find that you can't. If you try to press the button without having seen a flash, the flash immediately appears, and no matter how fast you move, you never push the button until a second has elapsed. If you wait for the flash, intending to keep from pressing the button afterwards, the flash never appears. No matter what you do, the light always precedes the button press. There's no way to fool a Predictor.

The heart of each Predictor is a circuit with a negative time delay - it sends a signal back in time. The full implications of the technology will become apparent later, when negative delays of greater than a second are achieved, but that's not what this warning is about. The immediate problem is that Predictors demonstrate that there's no such thing as free will.

There have always been arguments showing that free will is an illusion, some based on hard physics, others based on pure logic. Most people agree these arguments are irrefutable, but no one ever really accepts the conclusion. The experience of having free will is too powerful for an argument to overrule. What it takes is a demonstration, and that's what a Predictor provides.

Typically, a person plays with a Predictor compulsively for several days, showing it to friends, trying various schemes to outwit the device. The person may appear to lose interest in it, but no one can forget what it means - over the following weeks, the

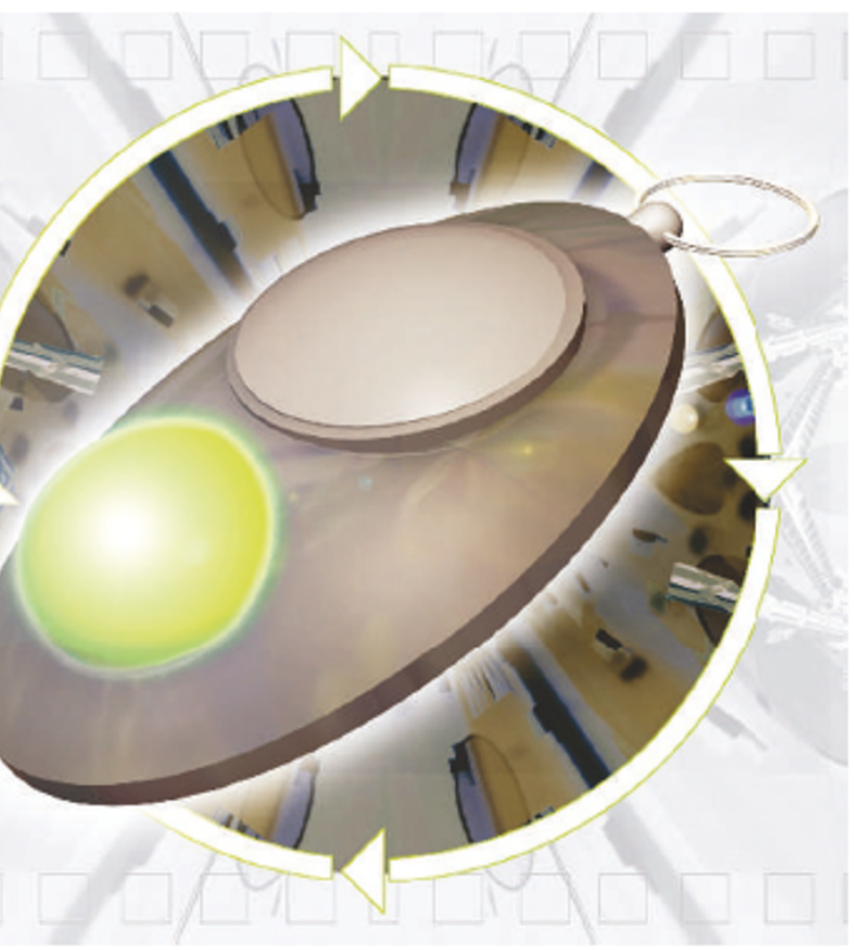

ably respond, ${ }^{\alpha}$ But now I know." And some of them never say anything again.

Some will argue that the fact the Predictor causes this change in behaviour means that we do have free will. An automaton cannot become discouraged, only a free-thinking entity can. The fact that some individuals descend into akinetic mutism whereas others do not just highlights the importance of making a choice.

Unfortunately, such reasoning is faulty: every form of behaviour is compatible with determinism. One dynamic system implications of an immutable future sink in. Some people, realizing that their choices don't matter, refuse to make any choices at all. Like a legion of Bartleby the Scriveners, they no longer engage in spontaneous action. Eventually, a third of those who play with a Predictor must be hospitalized because they won't feed themselves. The end state is akinetic mutism, a kind of waking coma. They'll track motion with their eyes, and change position occasionally, but nothing more. The ability to move remains, but the motivation is gone.

Before people started playing with Predictors, akinetic mutism was very rare, a result of damage to the anterior cingulate region of the brain. Now it spreads like a cognitive plague. People used to speculate about a thought that destroys the thinker, some unspeakable lovecraftian horror, or a Godel sentence that crashes the human logical system. It turns out that the disabling thought is one that weve all encountered: the idea that free will doesn't exist. It just wasn't harmful until you believed it.

Doctors try arguing with the patients while they still respond to conversation. We had all been living happy, active lives before, they reason, and we hadn't had free will then either. Why should anything change? ${ }^{\alpha}$ No action you took last month was any more freely chosen than one you take today," a doctor might say. "You can still behave that way now." The patients invari- might fall into a basin of attraction and wind up at a fixed point, whereas another exhibits chaotic behaviour indefinitely, but both are completely deterministic.

I'm transmitting this warning to you from just over a year in your future: it's the first lengthy message received when circuits with negative delays in the megasecond range are used to build communication devices. Other messages will follow, addressing other issues. My message to you is this: pretend that you have free will. It's essential that you behave as if your decisions matter, even though you know that they don't. The reality isn't important: what's important is your belief, and believing the lie is the only way to avoid a waking coma. Civilization now depends on self-deception. Perhaps it always has.

And yet I know that, because free will is an illusion, it's all predetermined who will descend into akinetic mutism and who won't. There's nothing anyone can do about it - you can't choose the effect the Predictor has on you. Some of you will succumb and some of you won't, and my sending this warning won't alter those proportions. So why did I do it?

Because I had no choice.

Ted Chiang is an occasional writer of science

fiction. His work can be found in his collection Stories of Your Life and Others, published by Pan Macmillan. 